\title{
Restraining Placental Growth
}

National Cancer Institute

\section{Source}

National Cancer Institute. Restraining Placental Growth. NCI Thesaurus. Code C20901.

Restraining Placental Growth involves mechanisms that impede continued expansion of the placenta. 